\title{
Application of Surfactant-modified Bentonite for Methylene Blue Adsorption from Aqueous Solution
}

\author{
DAVOUD BALARAK ${ }^{1}$, MARYAM BAZZI ${ }^{2}$, ZACCHEUS SHEHU ${ }^{3}$ \\ and KETHINENI CHANDRIKA**
}

\author{
'Department of Environmental Health, Health Promotion Research Center, \\ Zahedan University of Medical Sciences, Zahedan, Iran. \\ ${ }^{2}$ Department of Environmental Health, Student Research Committee, \\ Zahedan University of Medical Sciences, Zahedan, Iran. \\ ${ }^{3}$ Department of Chemistry, Faculty of Science Gombe State University, Nigeria. \\ ${ }^{4}$ Department of Petroleum Engineering, Koneru Lakshmaiah Education Foundation, \\ Vaddeswaram, Guntur, AP, India-52250. \\ *Corresponding authors E-mail: kkchandrika2019@gmail.com
}

http://dx.doi.org/10.13005/ojc/360212

(Received: February 10, 2019; Accepted: Aril 16, 2020)

\begin{abstract}
Dye is an important chemical and, recently, its application in the world has boosted; however the skin irritation and cancer are of the detrimental effects of this chemical. Therefore, prior to discharge, the dye-contain effluents, in order to meet the standard values, should be treated. The present work are seeking to appraise the kinetics and isotherms of the Methylene Blue (MB) adsorption onto the surfactant (cetyltrimethylammonium bromide)-modified bentonite (CTAB-MB) in a batch study in a laboratory. The study of the MB adsorption efficiency was accomplished in batch system under different amount of effective parameters including contact time, adsorbent dosages and $\mathrm{MB}$ dye concentration. Optimum CTAB-MB dosage and contact time was achieved to be $2.5 \mathrm{~g} / \mathrm{L}$ and $75 \mathrm{~min}$, respectively. The results of isotherm studies showed the better ability of Langmuir mono-layer isotherm in explanation of the equilibrium data and the highest adsorption capacity, based on this model, was obtained to be $36.19 \mathrm{mg} / \mathrm{g}$. According our obtained results, the CTAB-MB was obtained to be potent and efficient adsorbent to remove the MB from the studied synthetic solutions.
\end{abstract}

Keywords: Adsorption behavior, Methylene Blue, Surfactant-Modified Bentonite.

\section{INTRODUCTION}

The water pollution through the toxic substances has mentioned as a desperate issue because it affects various sectors of life cycle ${ }^{1,2}$. The textile industries have been identified as the basic industries in all countries, and the colorful wastewater is the main character of these industries, since the dyes are vastly consumed in these industries ${ }^{3,4}$. These industries remarkably use the synthetic

This is an Open Access article licensed under a Creative Commons license: Attribution 4.0 International (CC- BY). Published by Oriental Scientific Publishing Company @ 2018




dyes and the classifications of these types of dyes include acidic, reactive, direct, basic dyes, organic and mineral materials ${ }^{5,6}$. Methylene blue $(\mathrm{MB})$ is classified in the thiazine class and is a widely used cationic dye in the industries, e.g., textile, paper, plastics, food industries and medicine ${ }^{7,8}$.

Discharging the dye-contained wastewaters into the aquatic environment have created various obstacles such as aesthetic issues, disrupting the sunlight penetration into the deep layers and photosynthetic performance in aquatic plants; the evidence towards their undeniable role in eutrophication, rising the wastewaters hardness and turbidity, death and destruction of microorganisms in surface waters and gradual poisoning of human has been determined ${ }^{9-11}$.

Hence, these kinds of effluents are serious environmental risks which should be eliminated by the best methods prior to discharge into the aquatic media $^{12,13}$. The membrane separation, flocculationcoagulation, electrochemical, reverse osmosis, ozone oxidation, and biological treatments are of the extensively applied techniques to remove the dyes ${ }^{14,15}$. Despite their incredible efficiency and applicability in removing the dyes, the cost and complexity of these methods decreased the tendency to apply these methods ${ }^{16,17}$.

The adsorption is a valuable and economical alternative used for removing the pollutants which it has remarkable efficiency for recycling the adsorbent and adsorbate materials ${ }^{18,19}$. Numerous attempts have broadly conducted on various novel and common adsorbents and the activated carbon has introduced as the propitious adsorbent for elimination of the pollutants, since it has a great performance for this purpose ${ }^{20,21}$. Nevertheless, its large-scale application has the economic limitations, since it is expensive and is associated with high regeneration $\operatorname{cost}^{18}$.

Therefore, finding the novel and low-priced adsorbents has presently gained nice attention among the scientists ${ }^{22}$. In keeping with the reports, the adsorbent with the requisites such as the need for little processing, great abundance and being a by-product or waste of an industry is inexpensive ${ }^{23}$. Hence, the attention towards the natural adsorbents to exterminate various contaminants has recently increased ${ }^{24}$. The bentonite clay, as anatural adsorbents, is a mineral formed into a layer with one octahedral sheet and two silica sheets and it has a net negative charge because it has the broken bonds around the edges of the silica-alumina units ${ }^{25-27}$. This mineral has illustrated the remarkable and successful results in adsorbing the dyes and metal ions ${ }^{28,29}$ and it has identified to be as a strong adsorbent to eliminate the pollutants from the solutions ${ }^{29}$.

Conducting the present study was to assess the capability of CTAB-MB in removal of Methylene Blue dye under different values of the studied parameters including the contact time, dye concentration and CTAB-MB dosage on dye removal efficiency and Ultimately, to analyze the kinetic and isotherms of the process.

\section{EXPERIMENTAL}

\section{Materials}

Methylene blue (basic blue 9, C.I. 52015; $\mathrm{C}_{16} \mathrm{H}_{18} \mathrm{ClN}_{3} \mathrm{~S}_{3} \mathrm{H}_{2} \mathrm{O}$; MW, $373.90 \mathrm{~g} / \mathrm{mol}$ ) was used as the adsorbate and was purchased from Merck, Darmstadt, Germany. The obtained chemical formula was shown in the Figure 1.

\section{Preparation of adsorbate (CTAB-MB)}

For preparation of CTAB-MB, the amount of $25 \mathrm{~g}$ bentonite is poured in $250 \mathrm{~mL}$ of water with $5 \mathrm{~g}$ of CTAB and it is stirred at $25^{\circ} \mathrm{C}$ for 12 hours. The resultant is then filtered and washed with distilled water for several times and the CTAB-MB is dried at $110^{\circ} \mathrm{C}$ for $6 \mathrm{~h}(25)$. After preparation of adsorbent, its characteristics was assessed by BET method (Brunauer-Emmet-Teller) using liquid $\mathrm{N}_{2}$ adsorption at $196^{\circ} \mathrm{K}$ and the scanning electron microscopy (JEOL, model 6400).

\section{Batch Kinetics Experiments}

The stock solution used in this study (1000 $\mathrm{mg} / \mathrm{L}$ ) was provided by dissolving the required amount of $\mathrm{MB}$ in distilled water and then it was diluted using the deionized water to prepare the solutions with desired concentrations. The volume of dye solution (sample) was $200 \mathrm{~mL}$.

To implement the experiments, the batch system using round bottom flasks were utilized. For this purpose, a certain amount and volume of 
CTAB-MB adsorbent and $100 \mathrm{~mL}$ of MB solution with different was poured into $200 \mathrm{~mL}$ round bottom flasks and, after capping and placing on a mechanical shaker, they were shaken at $120 \mathrm{rpm}$ at $25^{\circ} \mathrm{C}$ for desired time. The resultant solutions were filtered using Millipore membrane filter of $0.45 \mu \mathrm{m}$ before analyses. The amount of adsorbed dye ions by CTAB-MB for each gram of adsorbent, adsorption capacity $\left(q_{\mathrm{e}}\right)$ and removal efficiency (\% removal) are identified by Eqs. (1) and (2) ${ }^{30}$

$$
\begin{aligned}
& \mathrm{q}_{\mathrm{e}}=\frac{\left(\mathrm{C}_{0}-\mathrm{C}_{\mathrm{e}}\right) \mathrm{V}}{\mathrm{m}} \\
& \% \mathrm{R}=\frac{\left(\mathrm{C}_{0}-\mathrm{C}_{\mathrm{e}}\right)}{\mathrm{C}_{0}} \times 100
\end{aligned}
$$

Where $q_{e}$ is the amount of adsorbed dye per mass unit of the adsorbent at equilibrium ( $\mathrm{mg} / \mathrm{g}), \mathrm{V}$ is the volume of the solution and $\mathrm{W}$ is the weight of the adsorbent. In addition $\mathrm{C}_{0}$ is the initial concentration of the dye $(\mathrm{mg} / \mathrm{L})$ and $\mathrm{C}_{e}$ is the dye concentration at the equilibrium $(\mathrm{mg} / \mathrm{L})$. All of the tests performed twice and the best results were reported. The measurement of dye concentration of the samples, after conducting the experiments, was carried out by UV-Vis Spectrophotometer (DR 5000) at a $\lambda_{\max }$ of $554 \mathrm{~nm}$.

The adsorption isotherms for the MB removal were studied using various concentrations. For this purpose, the linear forms of Langmuir, Freundlich and Temkin adsorption isotherm models were utilized. The following equations represent these models ${ }^{31,32}$

$$
\begin{array}{lr}
\frac{\mathrm{Ce}}{\mathrm{qe}_{\mathrm{e}}}=\frac{1}{\mathrm{q}_{\mathrm{m}} \mathrm{K}_{\mathrm{L}}}+\frac{\mathrm{C}_{\mathrm{e}}}{\mathrm{q}_{\mathrm{m}}} & \text { Langmuir } \\
\log q_{\mathrm{e}}=\log K_{\mathrm{F}}+\frac{1}{n} \log C_{\mathrm{e}} & \text { Freundlich } \\
\mathrm{q}_{\mathrm{e}}=\frac{\mathrm{RT}}{\mathrm{b}} \ln \left(\mathrm{k}_{\mathrm{T}} \mathrm{C}_{\mathrm{e}}\right) \quad B=\frac{R T}{b} & \text { Temkin }
\end{array}
$$

In this study, the kinetic studies of MB adsorption onto the CTAB-MB were done by the pseudo-first order kinetic model, pseudo-second order kinetic model and intra-particle diffusion model. The linear forms of these models are expressed as ${ }^{33,34}$

$$
\log \left(q_{e}-q_{t}\right)=\log q_{e}-\frac{K}{2.303} t \quad \begin{aligned}
& \text { first pseudo } \\
& \text { order Kinetic }
\end{aligned}
$$<smiles></smiles>

Fig. 1. Chemical structure of Methylene Blue

\section{RESULTS AND DISCUSSION}

The results of characterization of the CTAB$M B$ illustrated that the specific surface area and pore volume of the adsorbent are $49.8 \mathrm{~m}^{2} / \mathrm{g}$ and 0.016 $\mathrm{mL} / \mathrm{g}$, respectively. Moreover, Fig. $2 \mathrm{a}$ and $\mathrm{b}$ are related to the SEM images of bentonite and CTAB-MB.

Figure $3 \mathrm{a}$ and $\mathrm{b}$ are related to SEM images, applied for determination of surface morphology of bentonite and modified bentonite. These images display that there are few number particles in agglomerates of bentonite compared to modified bentonite. Moreover, the laminar crystalline habit characteristic of phyllosilicates was observed in several particles in both bentonite and modified bentonite show however, these types of particle are greater in CTAB-MB. The domination of relatively great laminar crystallites and agglomerates may also be due to the interaction of surfactant molecules in the interlayer ${ }^{28}$.

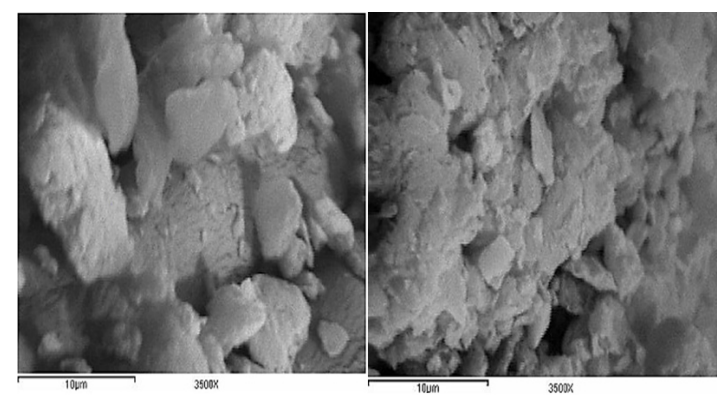

Fig. 2. SEM micrographs of Bentonite and CTAB-MB

Effect of contact time and initial MB concentration

Figure 3 reveals the effect of contact time and $\mathrm{MB}$ initial concentration on the $\mathrm{MB}$ removal efficiency. As it is clear, the MB efficiency decreased by increasing MB concentration from 10 to $100 \mathrm{mg} / \mathrm{L}$, 
but the adsorption capacity increased by increasing the initial MB concentration (Fig. 4). Furthermore, considering the Fig. 4, the MB removal efficiency was reduced by increasing the contact time from 10 to $150 \mathrm{~min}$.

Based on our results, the MB adsorption process had two stages; so that, in the first stage, the adsorption was carried out rapidly at $30 \mathrm{~min}$ and then, in second stage, the MB adsorption process had a slow trend and was performed during time of 30-75 min in this stage, in comparison with the first stage, the adsorption capacity was decreased. It was identified that, for the contact time higher than 75 min it has no significant effect on adsorption capacity. It can be remarked that, according to dynamic equilibrium, in this time, the levels of adsorption and desorption are the same. To explain what is happened in the studied process, it can be said that the mass transfer of dye molecules into boundary layer is rapidly occurred ${ }^{34,35}$. But, the releasing of the dye molecules from the boundary layer into the absorbent surface is slowly carried out which is because of the occupation of the active adsorption and dispersing the dyes molecule into the adsorbent pores ${ }^{36}$.

\section{Effect of adsorbent dosage}

Figure 5 depicts the effect of this parameter on MB adsorption efficiency. The adsorption efficiency was raised by increasing the CTAB-MB dosage up to $2.5 \mathrm{~g} / \mathrm{L}$ and the equilibrium was obtained after this dosage. In spite of increasing the adsorption efficiency, the adsorption amount per $\mathrm{g}$ of adsorbent dose $\left(q_{\mathrm{e}}\right)$ was decreased.

To explicate the effect of CTAB-MB dosage, determination of the $\mathrm{MB}$ removal efficiency was also carried out using different dosages of CTAB-MB $(0.2$ to $4 \mathrm{~g} / \mathrm{L})$ and it was found that increasing the adsorbent dosage has positive effect on MB removal efficiency and leads to its increase. Increasing adsorbent dosage may lead to promote the active sites, which it facilitates the MB adsorption efficiency. However, the adsorption capacity was decreased after certain point; this may be described by this fact that the overlapping or aggregation of adsorption sites may decrease the adsorption surface area ${ }^{37,38}$.

\section{Adsorption isotherm and kinetics}

Furthermore, based on the results, the adsorption capacity was developed by an increase in $\mathrm{MB}$ dye concentration. The increase of $\mathrm{MB}$ concentration is resulted in increase of the Mass transfer driving force and, as a result, the reaction between MB molecules and adsorbent is increased, which it is ultimately led to increasing the adsorption capacity $^{39,40}$. Results of Balarak et al., and Kumar et al., confirm our results ${ }^{16,41}$.

Table 1 represents the parameters of studied isotherm models. The coefficient of determination value of MB adsorption obtained from the Langmuir, Freundlich and Temkin models were $0.996,0.825$ and 0.811 , respectively.

Moreover, the parameters of kinetic studied were determined through the linear plot of $\log \left(q_{e}-q_{t}\right)$ versus t for the pseudo-first-order model (not shown), $\mathrm{t} / \mathrm{q}_{\mathrm{t}}$ versus $\mathrm{t}$ for the pseudo-second-order (shown in Fig. 6), and t 0.5 versus $q_{t}$ for intraparticle diffusion model (shown in Fig. 7); the values of the parameters were presented in Table 2.

Pseudo-first-order and pseudo-second-order models are considered as important models which, in present study, are employed to predict the mechanism of the adsorption of studied dye onto the CTAB-MB. Based on Table 2, the obtained data were strongly explained by pseudo-second-order model $\left(R^{2}>0.99\right)$. Similar result was obtained by Yagub et al., ${ }^{21}$.

The Langmuir is an isotherm model which is used to characterize the homogeneous adsorption which has equal sorption activation energy for the adsorption of each adsorbate molecule on to the adsorbent surface. The separation factor $\left(R_{L}\right.$, also called equilibrium parameter) is considered as an essential feature of the Langmuir isotherm and is a dimensionless constant and is expressed by the below equation ${ }^{19}$.

$R_{L}=1 /\left(1+K_{L} C_{0}\right)$

The $R_{L}$ values are indicative of the manner of the performing the adsorption based on following classification: for $R_{L}>1$, the adsorption is unfavorable; for $R_{L}=1$, it is linear; for $R_{L}$ between 0 and 1 , it is favorable; and for $R L=0$, it is irreversible.

Generally, the heat of adsorption, in adsorption process, decreases by increasing the adsorption. This is properly considered by the 
Freundlich isotherm. In addition, considering the assumption of this model, the adsorption of the pollutants is performed onto the heterogeneous adsorbent ${ }^{27}$. Also, according to assumptions of Temkin isotherm, the decreasing of adsorption heat of the surface molecules is not performed logarithmically and it carried out linearly; a uniform distribution of binding energies at the adsorbent surface specifies the adsorption process; and the adsorbate-adsorbent interaction is considered by this model ${ }^{40}$.

The $\left(R^{2}\right)$ related to the Langmuir isotherm was achieved to be 0.996, (Table 1) and it indicates that this isotherm model has a great aptness for explanation of the equilibrium data and the MB adsorption is a homogeneous. Moreover, the adsorption processes were favorable, since the separation factor $\left(R_{L}\right)$ was in the range of 0 and 1 (Table 2).

Furthermore, the intra-particle diffusion model was applied to further analyzing the kinetic results. Considering the Fig. 7, three stages for MB adsorption are observed. The highest adsorption is observed in the initial step of the process because of the powerful electrostatic attraction between MB and CTAB-MB. After that, the adsorption is performed gradually due to the intraparticle diffusion of MB molecules by CTABMB cavities. In third stage, as the intraparticle diffusion decreases, the final equilibrium stage appears; the high concentration of dye studied is the reason of this event. In addition, since the plots were not linear during the studied time range, it can be concluded that the ratelimiting mechanism in the MB adsorption process is not only the intra-particle diffusion and other mechanisms may play role in this case ${ }^{34,37}$.

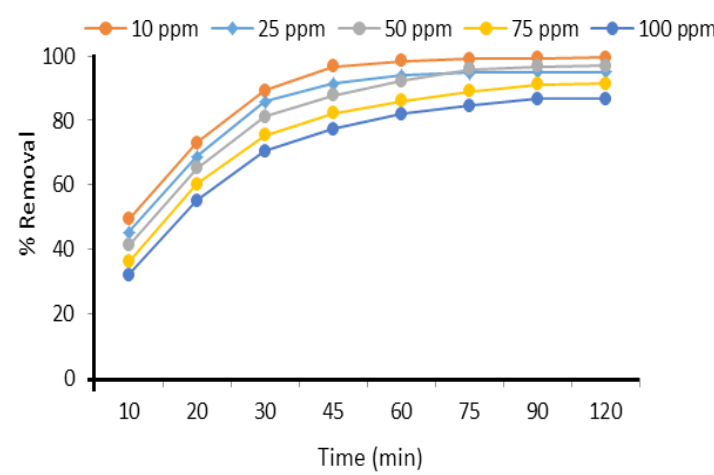

Fig. 3. Effect of contact time and concentration on MB dye removal efficiency $(\mathrm{pH}=7$ and adsorbent dose $=2.5 \mathrm{~g} / \mathrm{L}$ )

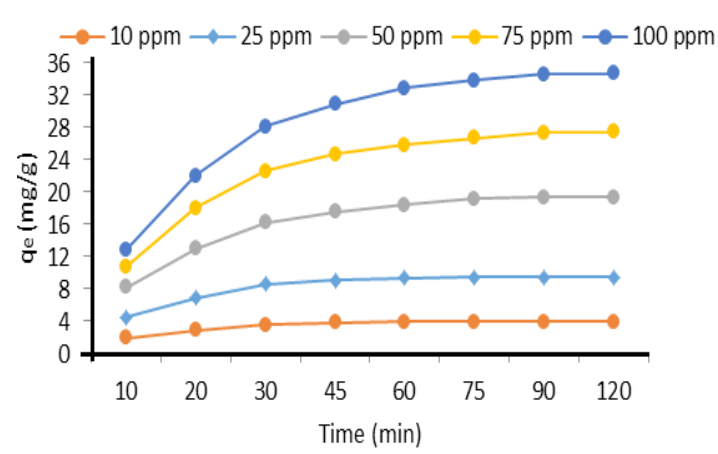

Fig. 4. Effect of contact time and concentration on adsorption capacity ( $\mathrm{pH}=7$ and adsorbent dose $=2.5 \mathrm{~g} / \mathrm{L}$ )

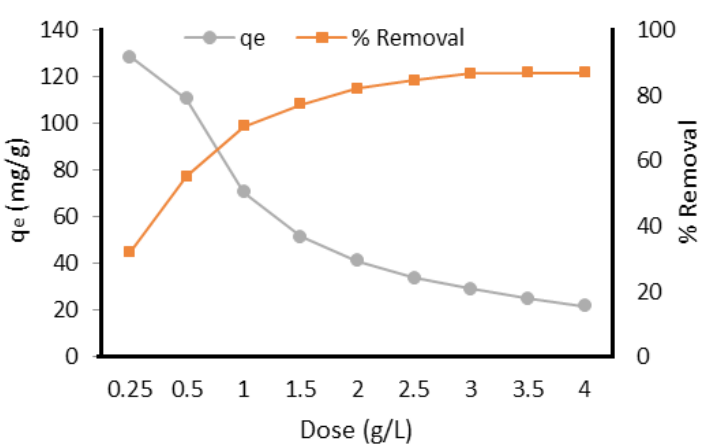

Fig. 5. Effect of adsorbent dose on MB dye removal efficiency $\left(\mathrm{C}_{0}=100 \mathrm{mg} / \mathrm{L}, \mathrm{pH}=7\right.$, Contact time $=75$ minute $)$

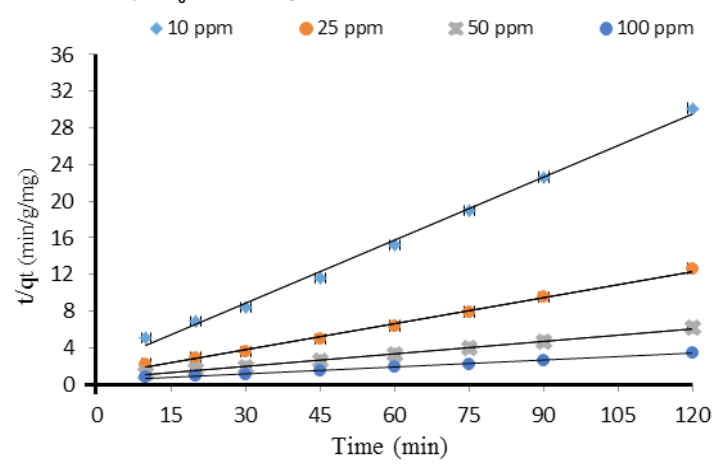

Fig. 6. Pseudo- second-order kinetics of $M B$ dye adsorption CTAB-MB (contact rime $=75 ; \mathrm{pH}=7$; dose; $2.5 \mathrm{~g} / \mathrm{L}$ )

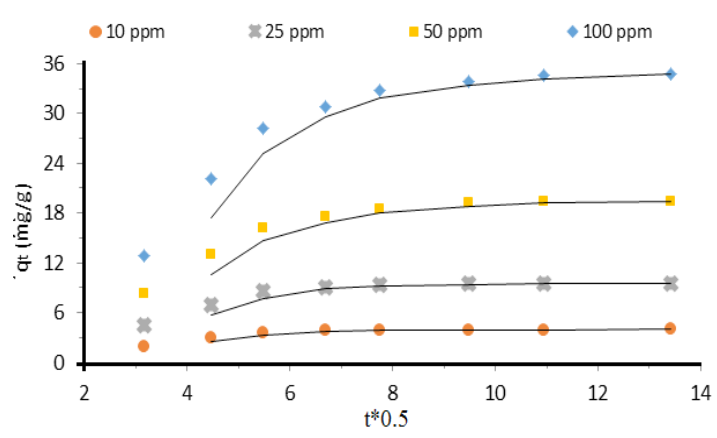

Fig. 7. Intraparticle diffusion kinetics of $M B$ dye adsorption CTAB-MB (contact rime=75; pH=7; dose; $2.5 \mathrm{~g} / \mathrm{L}$ ) 
Table 1: Isotherms constants for the removal MB onto CTAB-MB

\begin{tabular}{|c|c|c|c|c|c|c|c|c|c|c|c|c|}
\hline \multicolumn{4}{|c|}{ Langmuir model } & \multirow[b]{2}{*}{$\mathrm{R}^{2}$} & \multicolumn{4}{|c|}{ Freundlich model } & \multicolumn{4}{|c|}{ Temkin model } \\
\hline $\mathrm{q}_{\mathrm{m}}$ & $\mathrm{R}_{\mathrm{L}}$ & & $\mathrm{K}_{\mathrm{L}}$ & & \multicolumn{2}{|c|}{$n$} & $\mathrm{~K}_{\mathrm{F}}$ & $\mathrm{R}^{2}$ & \multicolumn{2}{|c|}{ A } & $B$ & $\mathrm{R}^{2}$ \\
\hline 36.19 & 0.039 & & 725 & 0.996 & \multicolumn{2}{|c|}{2.95} & 11.94 & 0.825 & \multicolumn{2}{|c|}{0.272} & 17.95 & 0.811 \\
\hline \multirow{2}{*}{\multicolumn{3}{|c|}{ MB Concentration (mg/L) }} & \multirow[t]{2}{*}{$\left(q_{e}\right)_{\exp }$} & \multicolumn{3}{|c|}{ Intraparticle diffusion } & \multicolumn{3}{|c|}{ Pseudo-first order } & \multicolumn{3}{|c|}{ Pseudo-second order } \\
\hline & & & & $\mathrm{k}$ & $\mathrm{C}$ & $\mathrm{R}^{2}$ & $\left(q_{e}\right)_{\text {cal }}$ & $\mathrm{K}$ & $\mathrm{R}^{2}$ & $\left(q_{e}\right)_{\text {cal }}$ & $\mathrm{K}$ & $\mathrm{R}^{2}$ \\
\hline & 10 & & 3.981 & 0.161 & 2.292 & 0.795 & 1.842 & 0.751 & 0.811 & 4.34 & 0.0097 & 0.996 \\
\hline & 25 & & 9.815 & 0.422 & 5.312 & 0.801 & 4.562 & 0.644 & 0.825 & 10.86 & 0.0095 & 0.998 \\
\hline & 50 & & 19.38 & 0.944 & 9.175 & 0.756 & 9.145 & 0.425 & 0.796 & 21.75 & 0.0037 & 0.997 \\
\hline & 100 & & 34.72 & 1.861 & 14.44 & 0.784 & 18.14 & 0.276 & 0.846 & 38.95 & 0.0014 & 0.999 \\
\hline
\end{tabular}

CONCLUSION

This work studied the potency of the surfactant-modified bentonite (CTAB-MB) in removal of $M B$ under different conditions of various parameters, i.e., contact time, initial concentration and CTAB-MB dosage. According to the results, the MB dye removal follows the Langmuir model $\left(R^{2}=0.996\right)$. Likewise, the CTAB$M B$ is a successful and effective adsorbent for
MB dye removal from aqueous solutions.

\section{ACKNOWLEDGEMENT}

The authors are grateful to Student Research Committee of Zahedan University of Medical Sciences because of supporting of this research.

\section{Conflicting interest}

There is no conflicting interest in this study.

\section{REFERENCES}

1. E.I. Unuabonah, K.O. Adebowale and F.A. Dwodu, J. Hazard. Mater., 2008, 157, 397-409.

2. B. Zohra, K. Aicha, S. Fatima, B. Nourredin and D. Zoubir, Chem. Eng. J., 2008, 136, 295-305.

3. V. Gómez, M.S. Larrechi and M.P. Callao, Chemosphere., 2007, 69, 1151-1158.

4. E. Bulut, M. Ozcar and I.A. Sengil, J Hazard Mater., 2008, 154, 613-622.

5. A.S. Ozcan and A. Ozcan, J Colloid Interf Sci., 2004, 276, 39-46.

6. B. Acemioðlu, J Colloid Interf Sci., 2004, 274, 371-379.

7. M.K. Purkait, A. Maiti, S. Das Gupta and S. De, J Hazard Mater., 2007, 145, 289-295.

8. Y.L. Song, J.T. Li and H. Chen, J Chem Technol Biot., 2009, 84, 578-583.

9. C. Liu, H.H. Ngo and W. K. Guo, Bioresource Technol., 2012, 119, 349-354.

10. S.V. Yadla, V. Sridevi and M.V.V.C. Lakshmi., Journal of Chemical, Biological and Physical Sciences., 2012, 2, 1585-1593.

11. F. Gonen, and D.S. Serin., African Journal of Biotechnology., 2012, 11, 1250-1258.

12. M.B. Ibrahim and S. Sani, Open Journal of
Physical Chemistry., 2014, 4, 139-146.

13. M.A.M. Salleh, D.K. Mahmoud, W.A. Karim and A. Idris, Desalination., 2011, 280, 1-13.

14. N. Sharma, D.P.Tiwari and S.K. Singh, Internat ional Journal of Scientific \& Engineering Research., 2012, 3, 1-10.

15. Balarak, D.; Mahdavi, Y.; Bazrafshan, E.; Mahvi, A. H. Fresenius. Environ. Bull., 2016, 25(5), 1321-30.

16. Ramachandran, P.; Vairamuthu, R.; Ponnusamy, S. Carbon., 2016, 6(11), 15-26.

17. Ayawei, N.; Ekubo, A.T.; Wankasi, D.; Dikio,E.D. Orient. J. Chem., 2015, 31(3), 1307-1308.

18. Vimonses, V.; Lei, S.; Jin, B.; Chow, C.W.K and Saint, C. Chemical Engineering Journal., 2009, 148(2-3), 354-364.

19. Yusra, S and Bhatti, H.N. Desalination., 2011, 272(1-3), 313-322.

20. Yaneva, Z.L. and Georgieva, N.V.International Review of Chemical Engineering., 2012. 4(2), 127-146.

21. Shin, E. W.; Rowell, R. M. Chemosphere., 2005, 60, 1054-1061. 
22. Balarak, D.; Azarpira, H. Int. J. ChemTech. Res., 2016, 9(9), 543-549.

23. Balarak, D.; Joghataei, A.; Azarpira, H.; Mostafapour, F. K. Int. J. Pharm. Technol., 2016, 8(3), 15780-88.

24. Amarasinghe, W. P. K.; Williams, R. A. J. Chem. Eng., 2007, 32, 299-309.

25. Yurtsever, M.; Sengil, I. A. J. Hazard. Mater., 2009, 163, 58-64.

26. Soylak, M.; Elci, L.; Akkaya, Y.; Dogan, M. Anal. Lett., 2002, 35, 487-499.

27. Balarak, D.; Azarpira, H. Int. J. ChemTech. Res., 2016, 9(7), 566-573.

28. Eren, E.; Afsin, B.; Onal, Y. J. Hazard. Mater., 2009, 161, 677-85.

29. Azarpira, H.; Mahdavi, Y. Pharma. Chem., 2016, 8(12), 61-67.

30. Balarak, D.; Azarpira, H.;Mostafapour, F. K. Pharma. Chem., 2016, 8(10), 243-247.

31. Zazouli, M. A.;Mahdavi, Y.;Bazrafshan, E. J. Environ. Health. Sci. Eng., 2014, 12(66), 1-5.

32. Diyanati, R. A.; Cherati, J. Y. J. Mazandaran Univ. Med. Sci., 2013, 22(2), 58-64.

32. Rozkhash, M.; Eslami, SV. J. Plant Prot. Res., 2015, 284, 579-588.

33. Balarak, D.; Jaafari, J.;Hassani, G.;Mahdavi, Y.;Tyagi, I.; Agarwal, S.; Gupta, V. K. Colloid Interface Sci. Commun., 2015, 7, 16-19.

34. Diyanati, R. A.; Yousefi, Z.; Cherati, J. Y. J. Mazandaran Univ. Med. Sci., 2013, 22(2), 13-21.

35. Diyanati, R. A.; Yousefi, Z.; Cherati, J. Y.; Balarak, D. J. Mazandaran Univ. Med. Sci., 2013, 23, 17-23.

36. Azarpira, H.; Mahdavi, Y.; Khaleghi, O. Pharm.
Lett., 2016, 8(11), 107-113.

37. Fuhrman, H. G.; Mikkelsen, P. S.; Ledin, A. Water. Res., 2007, 41, 591-602.

38. Balarak, D, Mostafapour, F. K.; Joghataei, A. Pharma. Chem., 2016, 8(8), 138-145.

39. Costodes, V. C. T.; Fauduet, H.; Porte, C.; Delacroix, A. J. Hazard. Mater., 2003, 103, 121-142.

40. Ashrafi, S. D.; Rezaei, S.; Forootanfar, H.; Mahvi, A. H.; Faramarzi, M. A. IntBiodeter. Biodegr., 2013, 85,173-181.

41. Pandey, K.; Sharma, S. K.; Sambi, S. S. Int. J. Environ. Sci. Tech., 2010, 7(2), 395-404.

42. Christoforidis, A. K.; Mitropoulos, A.C. Chem. Eng. J., 2015, 277, $334-340$.

43. Mata, Y. N.; Munoz, J. A. J. Hazard. Mater., 2009, 166, $612-618$.

44. Luo, D.; Xie, Y. F.; Tan, Z. L.; Li, X. D. J. Environ. Biol., 2012, 34, 359 - 365.

45. Balarak, D.; Azarpira, H.; Mostafapour, F. K. Pharma. Chem., 2016, 8(10), 114-121.

46. Li, Y. H.; Di, Z. C.; Wu, D. H.; Luan, Z. K.; Zhu, Y. Q. Water. Res., 2005, 39, 605-609.

47. Unlu, N.; Ersoz, M. J. Hazard. Mater., 2006, 136, 272-280.

48. Martins, B. L.; C. V.; Luna, A. S.; Henriques, A. C. Biochem. Eng. J., 2006, 27, 310-314.

49. Balarak, D.; Mahdavi, Y.; Bazrafshan, E.; Mahvi, A. H. Fresenius. Environ. Bull., 2016, 25(5), 1321-30.

50. Meng, Y. T.; Zheng, Y. M.; Zhang, L. M.; He, J. Z. Environ. Pollut., 2009, 157, 2577-2583.

51. Pacheco, S.; Tapia, J.; Medina, M. R.; Rodriguez, R. J. Non-Cryst. Solids., 2006, 352, 5475-5481. 